\title{
Organic Lecture: Teaching the Fluidity of Covalent Bonds
}

\section{ARTICLE}

Journal of Chemical Education

Douglass F. Taber*

Department of Chemistry and Biochemistry, University of Delaware, Newark, DE 19716

*taberdf@udel.edu

\section{Abstract:}

Covalent bonds are fluid, not rigid, as with hand-held plastic models. Raspberry jam is an effective visual demonstration of this fluidity.

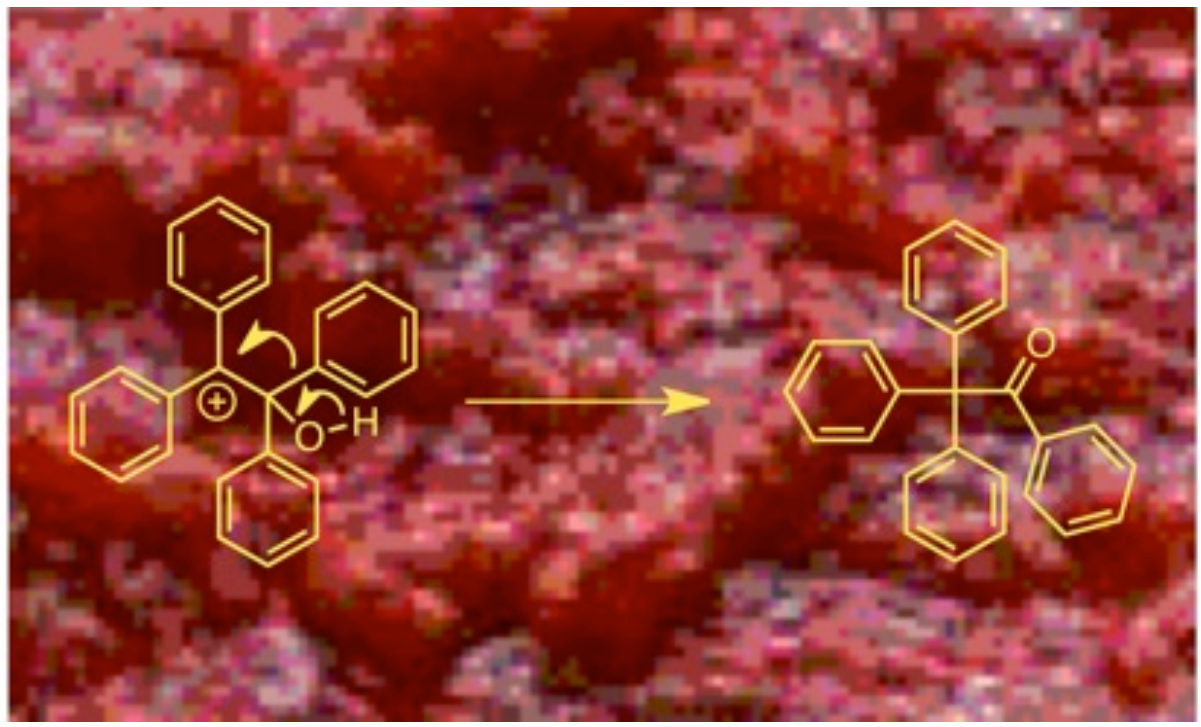

Key Words: Second-Year Undergraduate, Organic Chemistry, Analogies/Transfer, Mechanisms of Reactions, Covalent Bonding 


\section{Organic Lecture: Teaching the Fluidity of Covalent Bonds}

\section{Douglass F. Taber*}

Department of Chemistry and Biochemistry, University of Delaware, Newark, DE 19716

For 100 years, ${ }^{1}$ arrow-pushing mechanisms have been at the heart of the teaching of organic chemistry. Yet, even incoming Ph.D. students, who have had a full complement of undergraduate instruction, are not proficient at understanding and drawing such mechanisms. ${ }^{2}$ Several thoughtful strategies have been developed to more effectively help students gain that proficiency. $^{3}$

We commonly teach organic chemistry using plastic models (Fig. 1) that students can hold in their hands. These usefully communicate molecular shape, but they are not as effective for promoting understanding of organic reactivity.

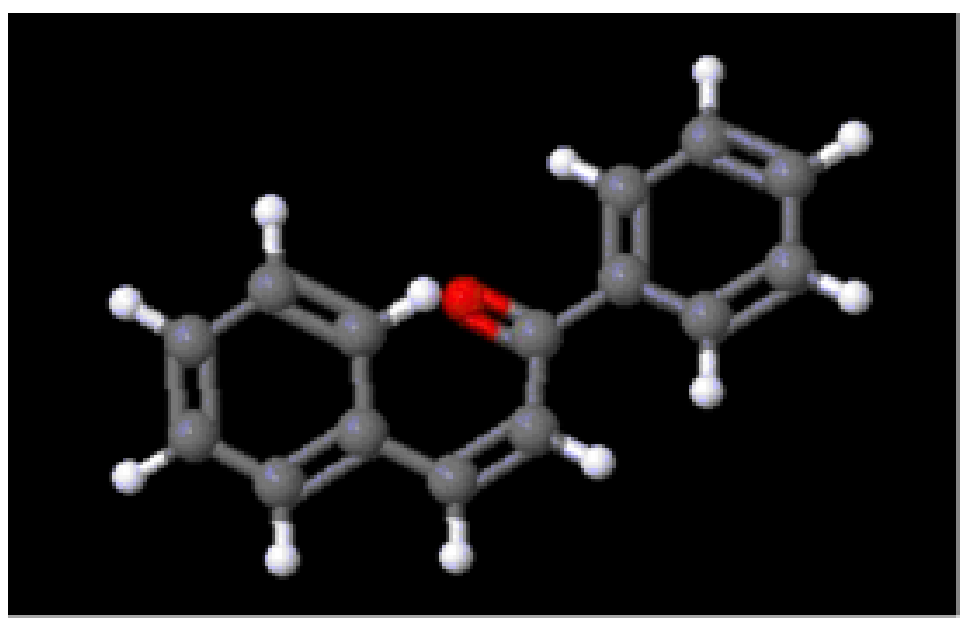

Figure 1. A plastic model of an organic molecule. 
To teach organic reactivity, we draw molecular diagrams using curved arrows (Fig. 2). ${ }^{4}$ We tell them that the curved arrows represent electron flow. They look at their plastic models, and do not see electrons.<smiles>CCC1=C(Cc2cccc(OC)c2)CCCC1=O</smiles>

Figure 2: Curved arrows represent electron flow.

Over thirty years of teaching organic chemistry to chemistry, biochemistry and chemical engineering majors, I have found it useful to explain to students, as they hold their plastic models, that a blob of raspberry jam (Fig. 3) is an equally good representation of an organic molecule. The seeds are the small positive nuclei, and the jelly is the electrons. The jelly is thicker between some nuclei - we call that a "bond". In fact, there is a whole field, Density Functional Theory, ${ }^{5}$ that describes that thickness quantititatively.

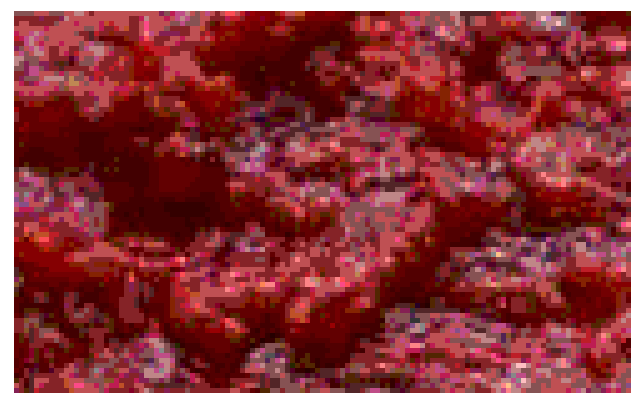

Figure 3. Raspberry jam.

To take the example of Fig. 2, the proton on the carbonyl has pulled electron density toward itself. The $\beta$-carbon of the enone is exposed, and looking for electron density. It finds the electron density in the benzene ring. 
Using this approach, both carbocations and alkyl free radicals can be seen as having lost electron density, like a chocolate-covered cherry with a bite out of it, with the red cherry, the positive nucleus, looking out, looking for electron density. Conversely, an anion has extra electron density, and is looking for some place to put it. Seeing organic reactivity this way makes it much easier for the students to understand "plastic bonds" being broken and formed. After the first month of class, students will only rarely draw arrows in the wrong direction. This approach is suitable even for the most elementary course in organic chemistry.

\section{Associated Content}

None

\section{Author Information}

Corresponding Author

*Email: taberdf@udel.edu

\section{Notes}

The author declares no competing financial interest.

\section{Literature Cited}

(1) Kermack, W. O.; Robinson, R. LI. An explanation of the property of induced polarity of atoms and an interpretation of the theory of partial valences on an electronic basis. J. Chem. Soc., Trans. 1922, 121, 427-440.

(2) Bhattacharyya, G.; Bodner, G.M. "It Gets Me to the Product": How Students Propose Organic Mechanisms. J. Chem. Educ. 2005, 82, 1402-1407.

(3) (a) Chen, J. H.; Baldi, P. Synthesis Explorer: A Chemical Reaction Tutorial System for Organic Synthesis Design and Mechanism Prediction. J. Chem. Educ. 2008, 85, 1699-1703. (b) Straumanis, A. R.; Ruder, S. M. New Bouncing Curved Arrow Technique for the Depiction of Organic Reaction Mechanisms. J. Chem. Educ. 2009, 86, 1389-1391. (c) Ruder, S. M.; Straumanis, A. R. A Method for Writing Open-Ended Curved Arrow Notation Questions for Multiple-Choice Exams and Electronic Response Systems. J. Chem. Educ. 2009, 86, 1392-1396. (d) Grove, N. P.; Cooper, M. M.; Rush, K. M. Decorating with Arrows: Toward the 
Development of Representational Competence in Organic Chemistry. J. Chem. Educ. 2012, 89, 844-849. (e) Grove, N. P.; Cooper, M. M.; Cox, E. L. Does Mechanistic Thinking Improve Student Success in Organic Chemistry? J. Chem. Educ. 2012, 89, 850-853. (f) Bhattacharyya, G. From Source to Sink: Mechanistic Reasoning Using the Electron-Pushing Formalism. J. Chem. Educ. 2013, 90, 1282-1289. (g) Crandell, O. M.; Kouyoumdijian, H.; Underwood, S. M.; Cooper, M. M. Reasoning about Reactions in Organic Chemistry: Starting It in General Chemistry. J. Chem. Educ. 2019, 96, 213-226. Crandell, O. M.; Lockhart, M. A.; Cooper, M. M. Arrows on the Page Are Not a Good Gauge: Evidence for the Importance of Causal Mechanistic Explanations about Nucleophilic Substitution in Organic Chemistry. J. Chem. Educ. 2020, 97, 313-327.

(4) Taber, D. F.; Sheth, R. B. A three-step route to a tricyclic steroid precursor. J. Org. Chem. 2008, 73, 8030-8032.

(5) Jeanmairet, G.; Levy, N.; Levesque, M.; Borgis, D. Introduction to Classical Density Functional Theory by a Computational Experiment. J. Chem. Educ. 2014, 91, 2112-2115.

TOC Graphic

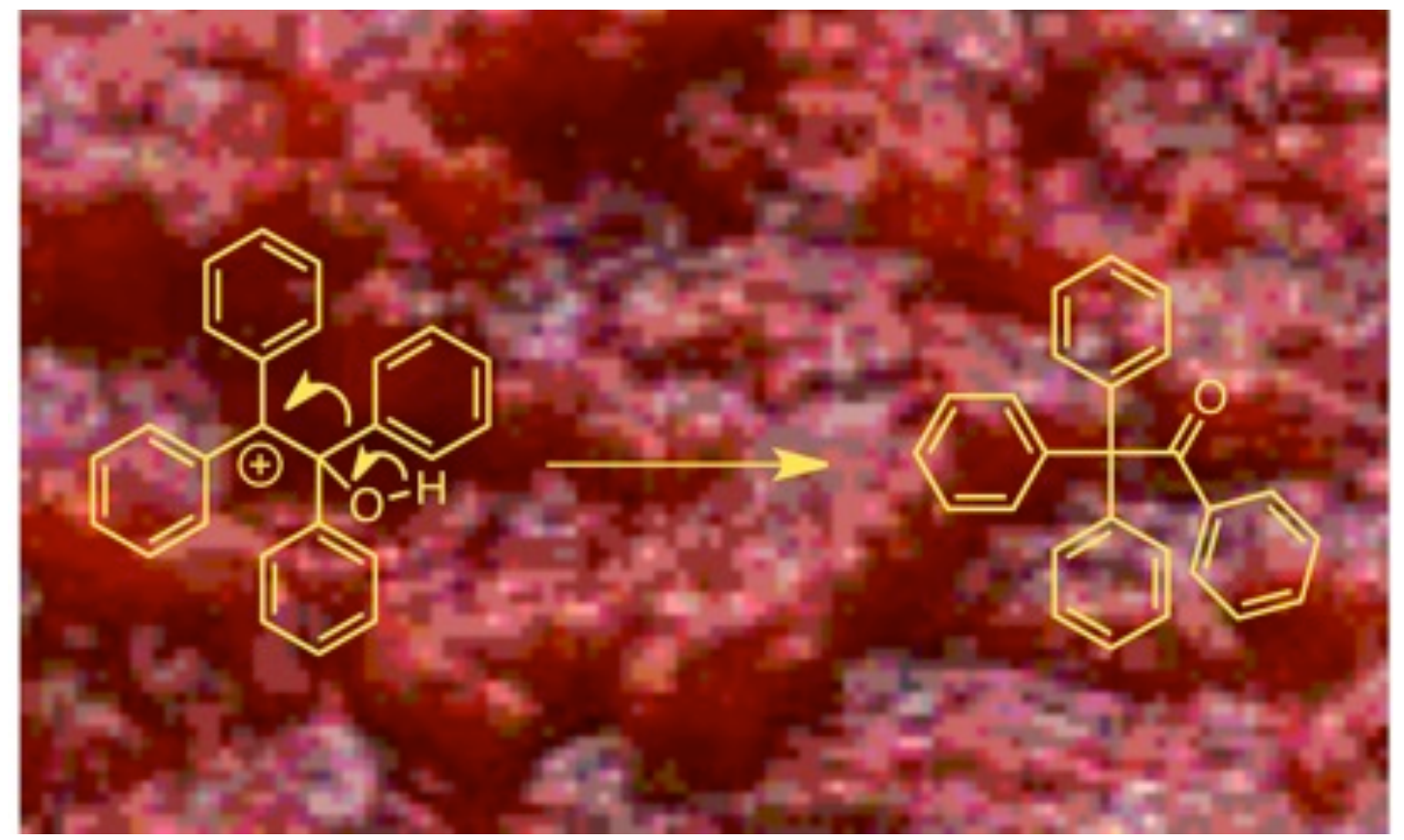

